Check for updates

Cite this: RSC Adv., 2020, 10, 9601

Received 6th January 2020

Accepted 16th February 2020

DOI: $10.1039 /$ dOra00132e

rsc.li/rsc-advances

\title{
Synthesis and characterization of hydroxyl- terminated butadiene-end-capped polyisobutylene and its use as a diol for polyurethane preparation
}

\author{
Kangda Wu, ${ }^{\text {ac }}$ Yibo Wu, (D) *ac Shan Huang, ${ }^{\text {bc }}$ Zhifei Chen, ${ }^{\text {bc }}$ Hao Wang, ${ }^{\text {ac }}$ \\ Yuwei Shang ${ }^{\text {ac }}$ and Shuxin Lic
}

Hydroxyl-terminated telechelic polyisobutylene (PIB) was prepared through living cationic polymerization. A living PIB chain was formed using the $t-\mathrm{Bu}-m$ - $\mathrm{DiCuOMe} / \mathrm{TiCl}_{4}$ initiating system and then capped with 1,3butadiene (BD) to prepare chlorine-terminated telechelic PIB. The chlorine-terminated telechelic PIB was then hydrolysed with tetrabutylammonium hydroxide to form hydroxyl-terminated PIB. Nuclear magnetic resonance spectroscopy confirmed hydrolysis completion. The hydroxyl-terminated PIB was subsequently used as a diol to react with 4,4-methylenebis(phenylisocyanate) (MDI) and produce a PIB-based polyurethane, which showed stronger acid resistance, hydrolysis stability and thermal oxidation stability than a commercial polyurethane.

\section{Introduction}

Polyisobutylene (PIB) is a fully saturated hydrocarbon elastomer with superior acid resistance, gas-barrier and mechanicaldamping characteristics, oxidative and chemical stability, and biocompatibility. ${ }^{1-6}$ The precise synthesis of hydroxyl telechelic PIB (HO-PIB-OH) compounds has attracted considerable commercial and scientific interest because of their versatility for further chemical modification and synthesis of hydrolysisresistant polyurethanes. ${ }^{7-11}$ In a recent study, Kennedy et al. synthesized HO-PIB-OH from $\mathrm{Br}-\mathrm{PIB}-\mathrm{Br}$ obtained from the quantitative anti-Markovnikov hydrobromination of Allyl-PIBAllyl. ${ }^{12,13}$ Storey et al. utilized thiol-ene click chemistry to produce $\mathrm{HO}-\mathrm{PIB}-\mathrm{OH}$ from telechelic exo-olefin-terminated PIB. ${ }^{14}$ Puskas et al. utilized direct functionalization with epoxide $/ \mathrm{TiCl}_{4}$ initiating systems. ${ }^{15-17} \mathrm{Wu}$ et al. reported the hydrolysis of PIBs end-capped with tert-butyl-dimethyl-(4methyl-pent-4-enyloxy)-silane to obtain HO-PIB-OH. ${ }^{18}$ Faust et al. synthesized HO-PIB-OH through the hydrolysis of chloroand bromoallyl PIBs derived from controlled/living cationic polymerization of isobutylene (IB) and end-capping with BD. ${ }^{19}$ The key to the synthesis of HO-Allyl-PIB-Allyl-OH is the development of a bifunctional initiator that can efficiently

${ }^{a}$ Beijing Key Lab of Special Elastomeric Composite Materials, Department of Materials Science and Engineering, Beijing Institute of Petrochemical Technology, Beijing 102617, China.E-mail: biptwkd@163.com; wangh@bipt.edu.cn; shangyuwei@bipt. edu.cn; lishuxin@bipt.edu.cn; wuyibo@bipt.edu.cn

${ }^{b}$ College of Material Science and Engineering, Beijing University of Chemical Technology, Beijing 100029, China. E-mail: h18811044437@163.com; chenzhifei1615@163.com

${ }^{c}$ Beijing Key Lab of Special Elastomeric Composite Materials, Beijing 102617, China initiate the living/controlled polymerization of IB. Therefore, in the present work, we compared the initiation effects of different bifunctional initiators and successfully synthesized HO-AllylPIB-Allyl-OH. We also discussed the factors affecting the synthesis of hydroxyl-terminated PIB in detail.

Polyurethane, as an important synthetic material, is characterized by a low relative density, good porosity, high specific strength, and high insulating property. Polyurethane is mainly obtained as a polyester or polyether and, as such, has high moisture permeability due to the disadvantages of the polarity of ester or ether bonds. Therefore, replacement of the soft segment of polyurethane with polymers, such as PIB and poly(tetramethylene oxide) (PTMO), has been attempted to enable the material's application to special environments. ${ }^{20-29}$ Thermoplastic polyurethane ureas (TPUUs) based on PTMO and PIB segments obtained by chain extension of PIB-diamine/PTMOdiol have excellent mechanical properties compared with conventional TPUs. If TPUU-based PTMO and PIB are obtained by incorporating $10-30 \%$ PTMO diol into the soft segment, the resulting ultimate tensile strength and elongation at break may be higher than that of conventional TPUs. ${ }^{30-34}$

HO-Allyl-PIB-Allyl-OH has been used as a precursor to synthesize PIB-based polyurethane. In this case, a hydroxylterminated telechelic PIB replaces a polyester (ether) polyol that is easily hydrolyzed and pyrolyzed so that the resistance of the resultant material to hydrolysis and heat is greatly improved. The polyurethane molecular chain produced by the reaction of hydroxyl-terminated telechelic PIB and isocyanate contains PIB segments, exhibits the excellent hydrolytic stability of PIB, and has low air permeability and great competitiveness in the market. 


\section{Experimental}

Materials

Titanium tetrachloride $\left(\mathrm{TiCl}_{4}\right)$ (99\%; Tokyo Chemical Industry Co.) were dried over phosphorus pentoxide $\left(\mathrm{P}_{2} \mathrm{O}_{5}\right)$ under $\mathrm{N}_{2}$ atmosphere for 12 hours before use, $n$-hexane (99.5\%; Beijing Yanshan Petroleum Chemical Co.) were refluxed and distilled with sodium under $\mathrm{N}_{2}$ atmosphere for 48 hours before use, 1,4butadiene (BD) (99\%; Beijing Yanshan Petroleum Chemical Co.) and isobutylene (IB) (99.9\%; Beijing Yanshan Petroleum Chemical Co.) were condensed in a cold bath in a glove box prior to polymerization. 5-tert-Butyl-bis(2-methoxy-2-propyl) benzene $(t$-Bu- $m$-DiCuOMe) was prepared by 5 -tert-butylisophthalic acid through grignard reaction. Methyl chloride $(\mathrm{MeCl})$ (99\%; Beijing Chemical Reagent Co.), commercial polyurethane (PU) (Pellethane5863, Lubrizol, $\mathrm{Mn}=10000 \mathrm{~g} \mathrm{~mol}^{-1}$ ), 4,4'methylenebis(phenyl isocyanate) (MDI) (97\%; Tokyo Chemical Industry Co.), tetrabutylammonium hydroxide (TBAH) (27wt\% solution in $\mathrm{H}_{2} \mathrm{O}$; Tokyo Chemical Industry Co.), stannous

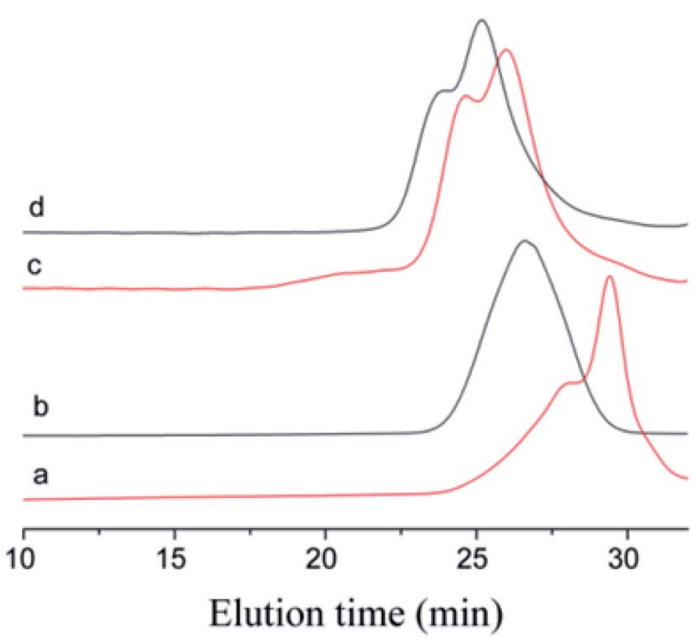

Fig. 1 GPC spectra of $\mathrm{Cl}-\mathrm{PIB}-\mathrm{Cl}$. (a) Initiated by $t-\mathrm{Bu}-m$-DiCuOMe in the presence of $\mathrm{DtBP}$, (b) initiated by $t-\mathrm{Bu}-m$-DiCuOMe in the absence of DtBP, (c) initiated by 1,3-bis-(1-chloro-1-methyl-ethyl)-benzene in the presence of DtBP, (d) initiated by 1,3-bis-(1-chloro-1-methylethyl)-benzene in the absence of DtBP. octoate $\left(\left(\mathrm{Sn}(\mathrm{Oct})_{2}\right)\right.$ (95\%; Tokyo Chemical Industry Co.), 1,4butanediol (BDO) (99\%; Tokyo Chemical Industry Co.), tetrahydrofuran (THF) (99.9\%; Tokyo Chemical Industry Co.), 2,6-ditert-butylpyridine (DtBP) (96\%; Tokyo Chemical Industry Co.), methanol (99\%; Beijing Chemical Reagent Co.), nitric acid (68\%; Beijing Chemical Reagent Co.) were used as received.

\section{Synthesis of Cl-Allyl-PIB-Allyl-Cl via carbocationic polymerization}

All polymerizations were carried out under a dry $\mathrm{N}_{2}$ atmosphere in a stainless steel glove box using $\mathrm{Hex} / \mathrm{MeCl}(40 / 60 \mathrm{v} / \mathrm{v})$ solvent mixtures. IB was initially polymerized in the $t$-Bu- $m$-DiCuOMe/ $\mathrm{TiCl}_{4} / \mathrm{D} t \mathrm{BP} /-80{ }^{\circ} \mathrm{C}$ initiating system for $40 \mathrm{~min}$ and then added with the BD stock solution via end-capping reaction. After $2 \mathrm{~h}$ of reaction, the polymerizations were terminated with prechilled methanol. After solvent evaporation, the product was dissolved in cyclohexane and washed with methanol to remove the uninitiated co-initiator. The processed product was dried at $45{ }^{\circ} \mathrm{C}$ in a vacuum oven for $24 \mathrm{~h}$ to a constant weight. The yield was $66.45 \mathrm{~g}$ (98.7\% conversion).

\section{Synthesis of HO-Allyl-PIB-Allyl-OH}

Cl-Allyl-PIB-Allyl-Cl (5.2 g) was dissolved in anhydrous THF (50 $\mathrm{mL}$ ) at room temperature in a $100 \mathrm{~mL}$ round-bottomed flask with vigorous stirring. Then, $12 \mathrm{~mL}$ of $27 \%$ ТВAH (w/w) aqueous solution $(0.2 \mathrm{~mol})$ was added to the reaction system. The solution was refluxed overnight under stirring. After $22 \mathrm{~h}$, the polymerizations were terminated with prechilled methanol. After solvent evaporation, the product was dissolved in cyclohexane and washed with methanol to remove the uninitiated TBAH. The processed product was dried at $45{ }^{\circ} \mathrm{C}$ in a vacuum oven for $24 \mathrm{~h}$ to a constant weight. The reaction yield was $4.91 \mathrm{~g}$ (98.2\% conversion).

\section{Synthesis of PIB-based polyurethane}

A representative synthesis process of PIB-based polyurethane is described as follows. A mixture of $5.2 \mathrm{~g}$ of HO-Allyl-PIB-Allyl$\mathrm{OH}(2.60 \mathrm{mmol}), 0.44 \mathrm{~g}$ of BDO (4.92 mmol), and $1.76 \mathrm{~g}$ of MDI (7.02 mmol) was dissolved in $20 \mathrm{~mL}$ of anhydrous THF. Then, $5.2 \times 10^{-3} \mathrm{~g} \mathrm{Sn}(\mathrm{Oct})_{2}\left(8.2 \times 10^{-3} \mathrm{mmol}\right)$ was added to the reaction at $65{ }^{\circ} \mathrm{C}$ for $4 \mathrm{~h}$. After completion of the reaction, the<smiles>CC(C)(Cl)c1cccc(C(C)(C)Cl)c1</smiles><smiles>CC(C)c1cccc(C(C)(C)Cl)c1</smiles>
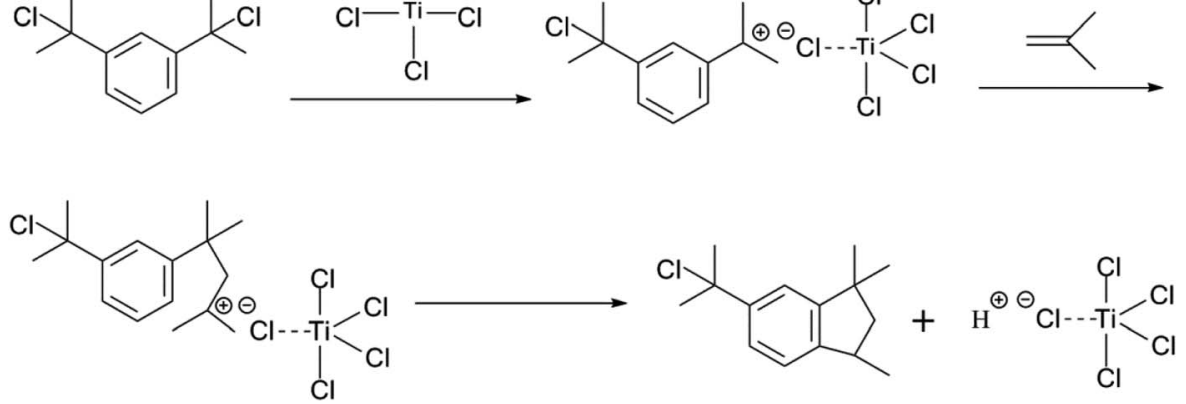

Fig. 2 Mechanism of the formation of an indanyl ring of 1,3-bis-(1-chloro-1-methyl-ethyl)-benzene. 
PIB-based polyurethane was rendered insoluble in organic solvents. The mixture was poured into a $7 \times 7 \mathrm{~cm}^{2}$ Teflon mold, the residual solvent was evaporated at room temperature, and the product was dried at $50{ }^{\circ} \mathrm{C}$ in a vacuum oven for $12 \mathrm{~h}$. Thus, the final product was obtained.

\section{Measurements}

${ }^{1} \mathrm{H}$ NMR spectroscopy was applied to understand the structural properties of the monomer and block copolymer composition with a Bruker $500 \mathrm{MHz}$ spectrometer using $5 \mathrm{~mm}$ O.D. tubes with the sample concentrations of $5-10 \%(\mathrm{~W} / \mathrm{V})$ in $\mathrm{CDCl}_{3}$ or $\mathrm{d}^{8}$ THF.

The gel permeation chromatography (GPC) spectra of the polymer for measuring the molecular weights and MWD $\left(M_{\mathrm{w}}\right)$ $M_{\mathrm{n}}$ ) were obtained using a model 510 HPLC pump, a model 410 differential refractometer, a model $441 \mathrm{UV} /$ visible detector, an online multiangle light-scattering detector and four GPC columns, which were connected in the following series: 500, $10^{3}, 10^{4}$ and $10^{5} \AA$. THF was used as the eluent at a flow rate of $1.0 \mathrm{~mL} \mathrm{~min}^{-1}$ at room temperature.

FT-IR spectra were obtained using a Shimadzu FTIR 8300 spectrophotometer equipped with a Smart Diamond ATR head at $2 \mathrm{~cm}^{-1}$ resolution in the 400 to $4000 \mathrm{~cm}^{-1}$ range.

Stress-strain tests were carried on an electronic universal testing machine (Instron3366, USA). The stretch rate was 40 $\mathrm{mm} \mathrm{min}^{-1}$. The samples $(2.0 \mathrm{~mm}$ width at the neck, $25 \mathrm{~mm}$ long) were shaped with an ASTM standard die. All the samples were tested under room temperature with a load cell of $0.1 \mathrm{kN}$ and a constant cross head speed of $250 \mathrm{~mm} \mathrm{~min}^{-1}$. The final report was the average of three measurements.

\section{Results and discussion}

\section{Synthesis of Cl-Allyl-PIB-Allyl-Cl via living cationic polymerization}

The choice of bifunctional initiator is particularly important in the preparation of PIB telechelic polymers. 1,3-Bis-(1-chloro-1methyl-ethyl)-benzene is a bifunctional initiator used

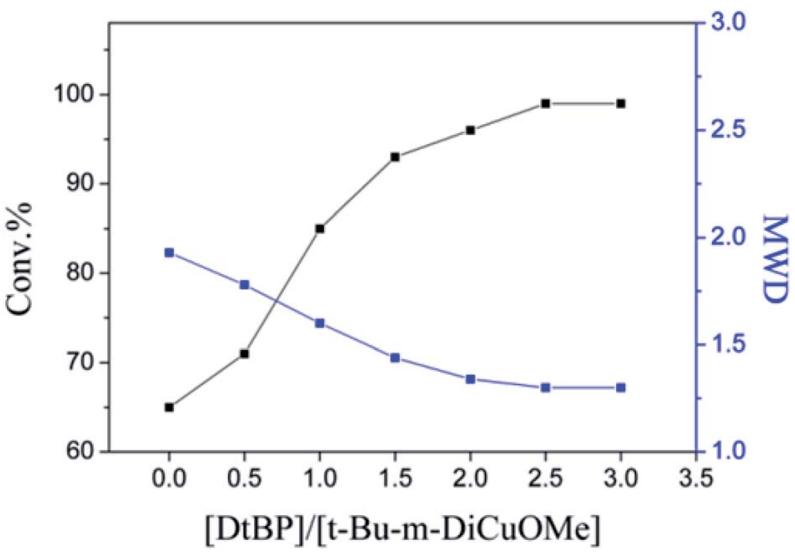

Fig. 3 Influence of the ratio of [DtBP]/[t-Bu-m-DiCuOMe] on the polymerization of $\mathrm{Cl}-\mathrm{PIB}-\mathrm{Cl}$.

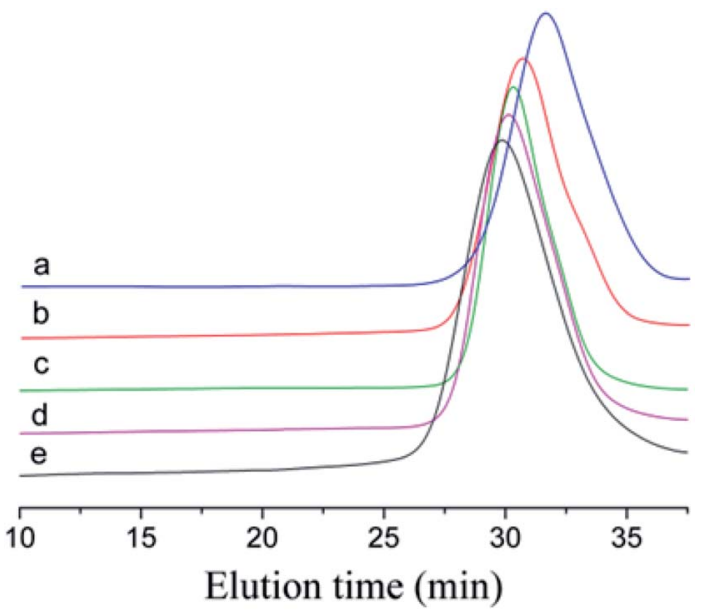

Fig. 4 GPC spectrum of $\mathrm{Cl}-\mathrm{PIB}-\mathrm{Cl}$ terminated at (a) $5 \mathrm{~min}$, (b) $10 \mathrm{~min}$, (c) $20 \mathrm{~min}$, (d) $30 \mathrm{~min}$, and (e) $40 \mathrm{~min}$.

worldwide in the field of carbocationic polymerization. Fig. 1 shows the GPC spectra of PIBs initiated by 1,3-bis-(1-chloro-1methyl-ethyl)-benzene and $t$-Bu- $m$-DiCuOMe. The GPC spectrum of PIB initiated by 1,3-bis-(1-chloro-1-methyl-ethyl)benzene in the (c) presence and (d) absence of DtBP shows a bimodal peak and wide MWD that may be attributed to the absence of tert-butyl in the benzene ring. As shown in Fig. 2,
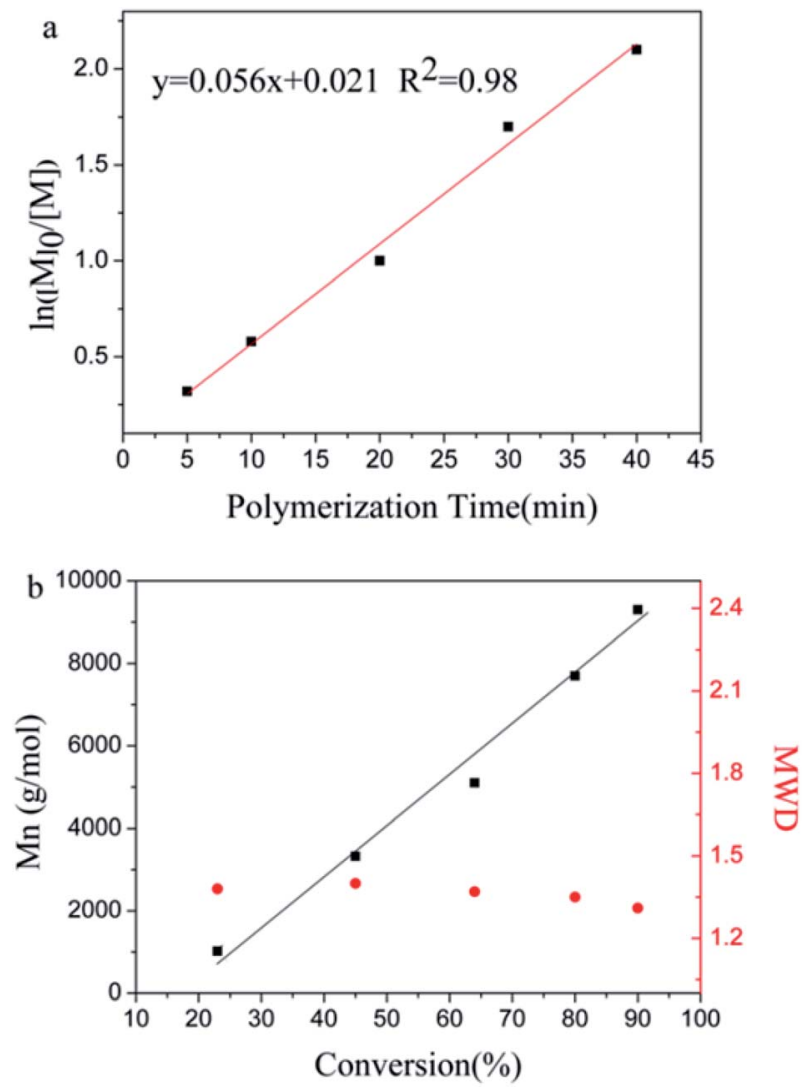

Fig. 5 (a) Time-conversion and (b) first-order kinetic plots of the living cationic polymerization of IB. 
<smiles>C=C(C)C(C)(C)c1cc(C(C)(C)C)cc(C(C)(C)OC(C)(C)c2cc(C(C)(C)OC)cc(C(C)(C)OC)c2)c1</smiles>

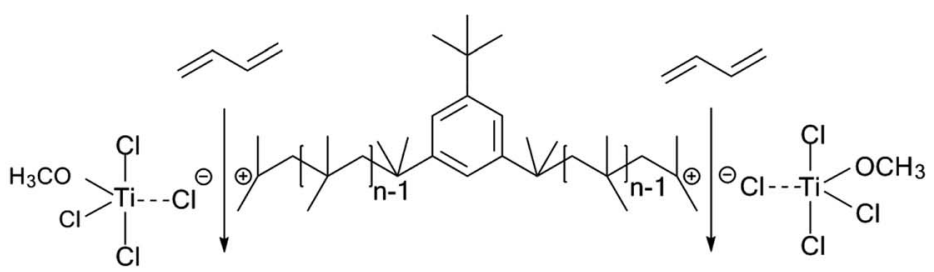

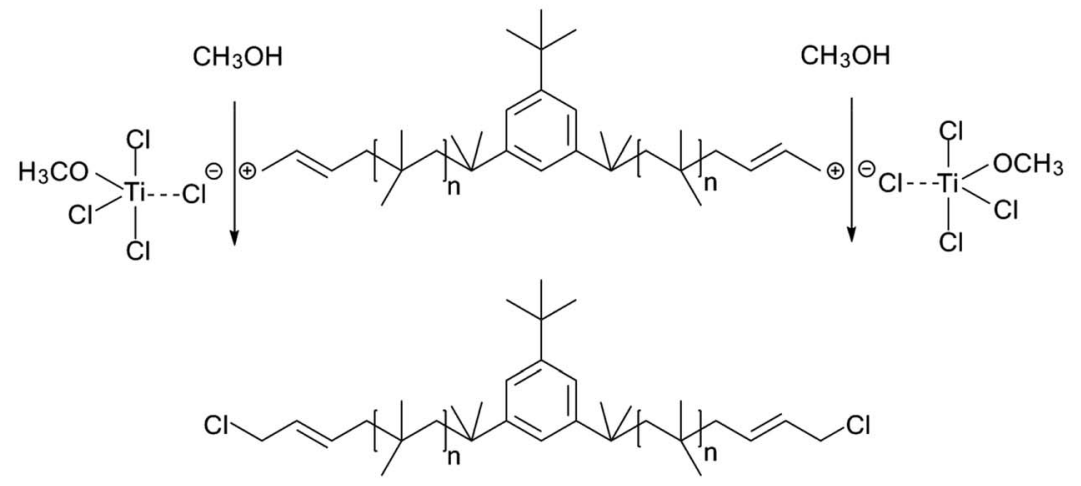

Fig. 6 Mechanism of $\mathrm{Cl}$-Allyl-PIB-Allyl-Cl synthesis in the $t$-Bu- $m$-DiCuOMe/ $\mathrm{TiCl}_{4}$ initiating system via carbocationic polymerization in Hex/ $\mathrm{MeCl} 60 / 40(\mathrm{v} / \mathrm{v})$ at $-80^{\circ} \mathrm{C}$.

without this bulky group, intramolecular aromatic alkylation occurs with the formation of an indanyl ring, which leads to unacceptable living polymerization. ${ }^{35}$ Fig. 1 (a) presents the GPC spectrum of PIB initiated by $t$-Bu- $m$-DiCuOMe in the absence of D $t$ BP. The GPC spectrum of the polymer shows a bimodal peak, and the molecular weight obtained is remarkably lower than the theoretical value. This finding indicates that chain transfer phenomena occur in the absence of $\mathrm{D} t \mathrm{BP}$ during polymerization. Such phenomena may be attributed to protons from the trace water and $\beta-\mathrm{H}$ at the end of growth chains in the $\mathrm{Hex} / \mathrm{MeCl}$ reaction system, which can complex with $\mathrm{TiCl}_{4}$ to form a proton living center and initiate the uncontrolled polymerization of the IB monomer. As shown in Fig. 1(b), the GPC spectrum of PIB initiated by $t$-Bu- $m$-DiCuOMe in the presence of $\mathrm{D} t \mathrm{BP}$ shows the theoretical molecular weight $\left(M_{\mathrm{n}}=9600, \mathrm{MWD}=1.18\right)$, which indicates that addition of $\mathrm{D} t \mathrm{BP}$ can maintain carbocation stabilization; intercept protons produced by impurities, waterproducing protons, and chain-end $\beta-\mathrm{H}$ growth during the initiation phase; ensure the singularity of living species; and achieve controlled initiation and growth. Thus, D $t \mathrm{BP}$ can inhibit undesirable side reactions, such as uncontrolled initiation of protons and chain-transition reactions of growing chains with monomers, and maintain living species to continue the efficient initiation of controlled IB polymerization. Fig. 3 illustrates the influence of the ratio of [DtBP]/[t-Bu- $m$-DiCuOMe] on the polymerization of PIB. Here, the conversion rate increased with increasing $\mathrm{D} t \mathrm{BP}$ content. When the ratio of $[\mathrm{D} t \mathrm{BP}] /[t-\mathrm{Bu}-m$-DiCuOMe] was 2.5 , the conversion rate and MWD reached $100 \%$ and 1.3 , respectively. In summary, PIB synthesis initiated by $t$-Bu- $m$-DiCuOMe in the presence of $\mathrm{D} t \mathrm{BP}$

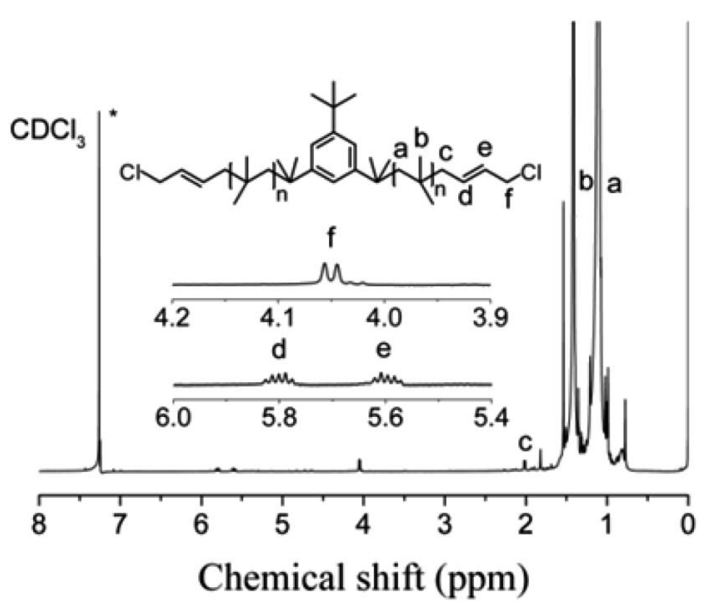

Fig. $7{ }^{1} \mathrm{H}$ NMR spectrum of Cl-Allyl-PIB-Allyl-Cl obtained after the capping reaction with $\mathrm{BD}$ in $\mathrm{Hex} / \mathrm{MeCl} 60 / 40(\mathrm{v} / \mathrm{v})$ at $-80{ }^{\circ} \mathrm{C}$. Peaks marked * belong to $\mathrm{CDCl}_{3}$. Experimental conditions: $t-\mathrm{Bu}-m$ DiCuOMe $=7.48 \times 10^{-3} \mathrm{~mol} \mathrm{TiCl}_{4}=1.34 \times 10^{-1} \mathrm{~mol}, \mathrm{DtBP}=1.87 \times$ $10^{-2} \mathrm{~mol}, \mathrm{IB}=1.2 \mathrm{~mol}, \mathrm{BD}=7.48 \times 10^{-2} \mathrm{~mol}$. 
<smiles>CC(C)(CC=CCCl)CC=Cc1cc(C(C)(C)CC=CCCl)cc(C(C)(C)CC(C)(C)CC=CCCl)c1</smiles><smiles>CC(C)(CC=CCO)CC(C)(C)CC(C)(C)CC(C)(C)CC=CCO</smiles>

Fig. 8 Synthesis of $\mathrm{HO}-\mathrm{Allyl}-\mathrm{PIB}-\mathrm{Allyl}-\mathrm{OH}$ via hydrolysis with $\mathrm{Cl}-$ Allyl-PIB-Allyl-Cl.

can meet our requirements of controllable $M_{\mathrm{n}}$ and low MWD with high efficiency.

To prove that the initiating system coupled with $t$-Bu- $m$ DiCuOMe/TiCl 4 can initiate the living cationic polymerization of IB, we designed a series of polymerization reactions using the same conditions but terminated at different times of 5, 10, 20, 30 and $40 \mathrm{~min}$ to analyze their first-order kinetic plots. Fig. 4 shows the GPC spectra of PIBs initiated by $t$-Bu- $m$-DiCuOMe and collected at various times. The PIB peak shifted toward higher molecular weights with increasing polymerization time. All of the polymers are clearly symmetrical and unimodal with a narrow distribution of molecular weights. Fig. 5(a) shows the time-conversion and first-order kinetic plots of the living cationic polymerization of IB. Here, $\ln \left([M]_{0} /[M]\right)$ varied linearly with the reaction time, thus confirming that the concentration of living centers remains constant. ${ }^{36}$ Fig. 5(b) reveals that the Mn of PIB increased in direct proportion to monomer conversion and approached the theoretical value. Moreover, MWD remained constant at nearly 1.2. This behavior validates the supposition that the controlled living cationic polymerization of

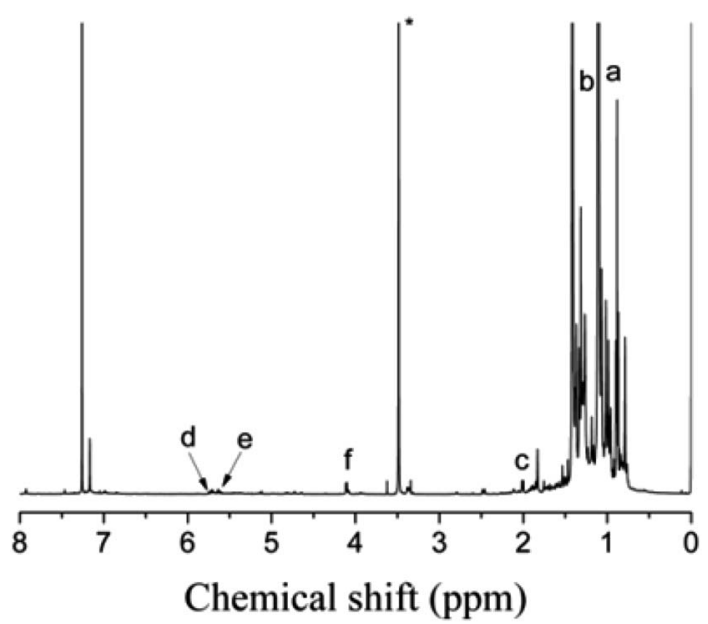

Fig. $9{ }^{1} \mathrm{H}$ NMR spectrum of $\mathrm{HO}-$ Allyl-PIB-Allyl-OH obtained after hydrolysis. Peaks marked * belong to $\mathrm{CH}_{3} \mathrm{OH}$.

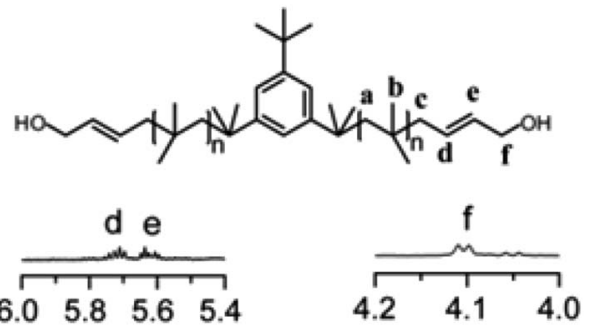

Reaction time:22h
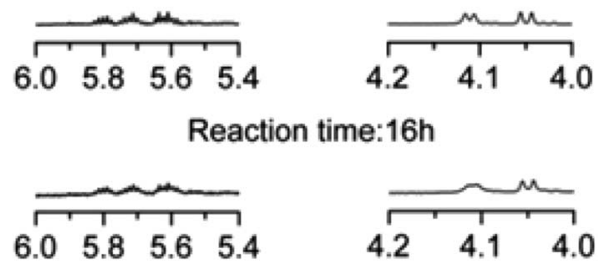

Reaction time: $10 \mathrm{~h}$

Fig. 10 Effect of hydrolysis time on Cl-Allyl-PIB-Allyl-Cl.

IB can be synthesized by $t$-Bu- $m$-DiCuOMe/TiCl ${ }_{4}$ in $\mathrm{Hex} / \mathrm{MeCl}$ and further confirms the reliability of the initiator.

The cationic polymerizations of IB with $t$-Bu- $m$-DiCuOMe/ $\mathrm{TiCl}_{4}$ initiating systems were conducted in $\mathrm{Hex} / \mathrm{MeCl} 60 / 40$ (v/v) at $-80{ }^{\circ} \mathrm{C}$ in the presence of $\mathrm{D} t \mathrm{BP}$. Fig. 6 illustrates the mechanism of PIB. During polymerization, $t$-Bu- $m$-DiCuOMe and $\mathrm{TiCl}_{4}$ combine and age to form a living carbocation center. Then, the IB monomer is added and initiated by the living center to form the living end of IB and initiate its chain growth. After 40 min of reaction, BD was added via end-capping reaction to attach PIB to both ends of the allylic structure. Finally, methanol is added to quench PIB and form an end-group allyl chlorine. Fig. 7 shows the ${ }^{1} \mathrm{H}$ NMR spectrum of Cl-Allyl-PIBAllyl-Cl obtained via living cationic polymerization with the $\mathrm{t}$ $\mathrm{Bu}-m$-DiCuOMe$/ \mathrm{TiCl}_{4}$ initiating system in the presence of $\mathrm{D} t \mathrm{BP}$

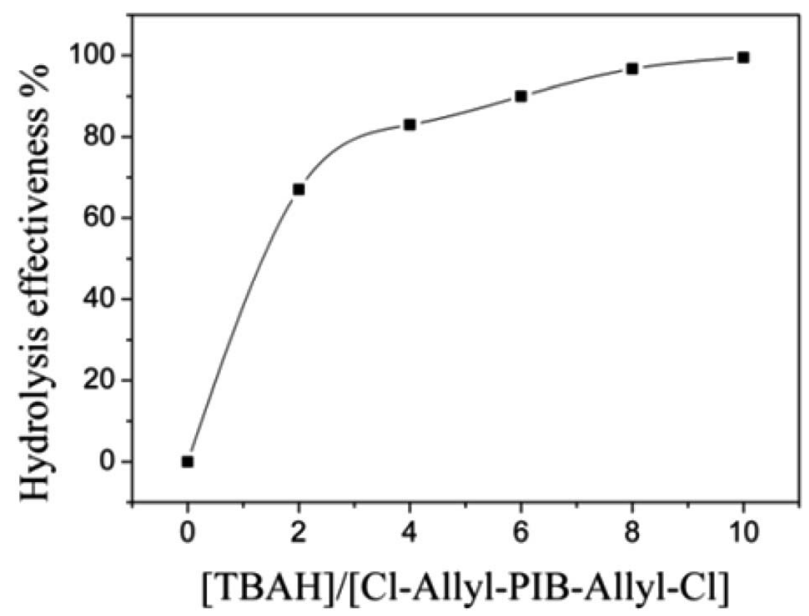

Fig. 11 Influence of the ratio of [TBAH]/[Cl-Allyl-PIB-Allyl-Cl] on the effectiveness of hydrolysis during the polymerization of $\mathrm{HO}-$ Allyl$\mathrm{PIB}-\mathrm{Allyl}-\mathrm{OH}$. 


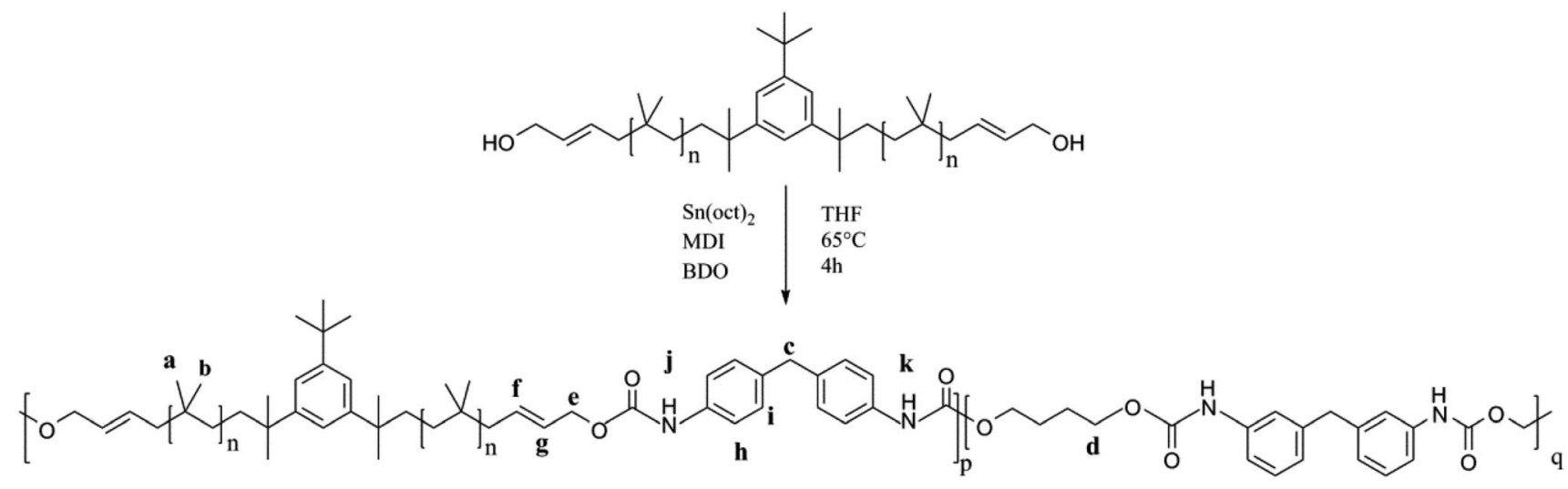

Fig. 12 Synthesis of the PIB-based polyurethane.

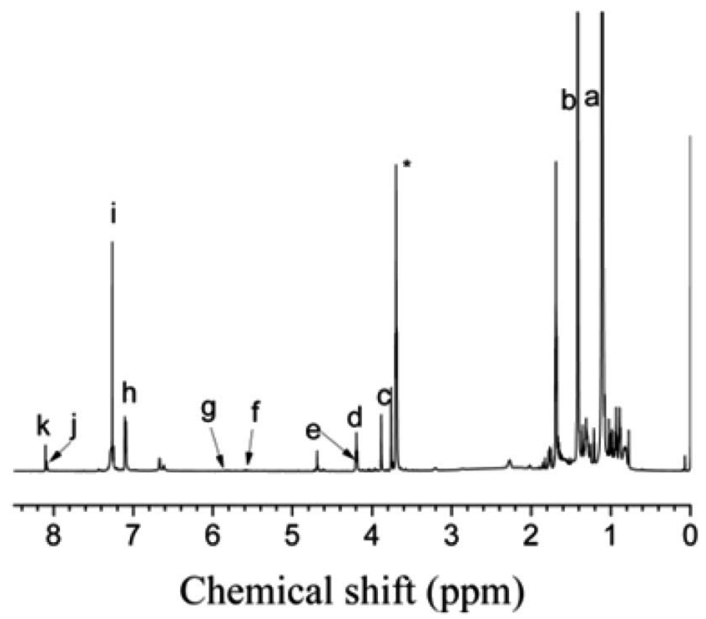

Fig. $13{ }^{1} \mathrm{H}$ NMR spectrum of the PIB-based polyurethane. Peaks marked * belong to $\mathrm{CH}_{3} \mathrm{OH}$.

and end-capping reaction with $\mathrm{BD}$. A dual characteristic resonance signal at $\mathrm{f}(4.05 \mathrm{ppm})$, which corresponds to the $\mathrm{H}$ proton in $-\mathrm{CH}_{2}$ - linked to the PIB group of the terminal allyl chlorine, could be observed. Multiple characteristic resonance signals are shown in $\mathrm{d}(5.81 \mathrm{ppm})$ and e (5.61 ppm), corresponding to the $\mathrm{H}$ proton in $\mathrm{C}=\mathrm{C}$ in the $\mathrm{PIB}$ terminal $\mathrm{BD}$, and the ratio of characteristic peak areas is $\mathrm{c}: \mathrm{d}: \mathrm{e}=2: 1: 1$. This result confirms that the end-capping reaction was completed. Thus, on the basis of the ${ }^{1} \mathrm{H}$ NMR results, Cl-Allyl-PIB-Allyl-Cl was successfully prepared through cationic polymerization.

\section{Synthesis of HO-Allyl-PIB-Allyl-OH}

Allyl halides are easily hydrolyzed to the corresponding enols in the presence of an inorganic base. Hence, Cl-Allyl-PIB-Allyl-Cl is a better choice for hydrolytic reactions than Cl-PIB-Cl. The hydrolytic reaction includes homogeneous and heterogeneous reaction systems. The homogeneous reaction system does not require high reaction temperatures, high pressures, or long reaction times. The product of the homogeneous reaction is easier to separate and purify than the product of the heterogeneous reaction system. In the present experiment, a homogeneous system was adopted to produce PIB with high quality hydroxyls at the end groups (HO-Allyl-PIB-Allyl-OH). The hydrolytic reaction of Cl-Allyl-PIB-Allyl-Cl was carried out in a homogeneous THF system to which TBAH was added (Fig. 8) according to the ${ }^{1} \mathrm{H}$ NMR spectrum (Fig. 9) of the hydrolysis-based Cl-Allyl-PIB-Allyl-Cl and TBAH. The peaks at 5.81 and $5.61 \mathrm{ppm}\left(-\mathrm{CH}=\mathrm{CH}-\mathrm{CH}_{2}-\mathrm{Cl}\right)$ increased over time and shifted to a (5.72 $\mathrm{ppm})$ and b (5.63 $\mathrm{ppm})$, which correspond to the $\mathrm{H}$ proton in $\mathbf{C H}=\mathrm{CH}-\mathrm{CH}_{2}-\mathrm{OH}$. After $22 \mathrm{~h}$, the chloromethylene proton peak $\left(-\mathrm{CH}=\mathrm{CH}-\mathrm{CH}_{2}-\mathrm{Cl}\right)$ at 4.05 ppm disappeared and the hydroxymethylene proton peak $(-\mathrm{CH}=\mathrm{CH}-$ $\mathrm{CH}_{2}-\mathrm{OH}$ ) appeared at $4.10 \mathrm{ppm}$. Thus, according to the ${ }^{1} \mathrm{H}$ NMR spectrum, the formation of HO-Allyl-PIB-Allyl-OH could be verified. Fig. 11 shows the hydrolysis effectiveness of the ratio of TBAH to Cl-Allyl-PIB-Allyl-Cl on hydrolysis. Under the premise that the reaction time is set to $22 \mathrm{~h}$ (Fig. 10), the hydrolytic effectiveness increases with increasing ratio of reactants. In particular, when the ratio reaches 10 , the hydrolytic effectiveness approaches $100 \%$.

\section{Synthesis of PIB-based polyurethane}

As shown in Fig. 12, PIB-based polyurethane is typically produced via nucleophilic addition between the hydroxyl group

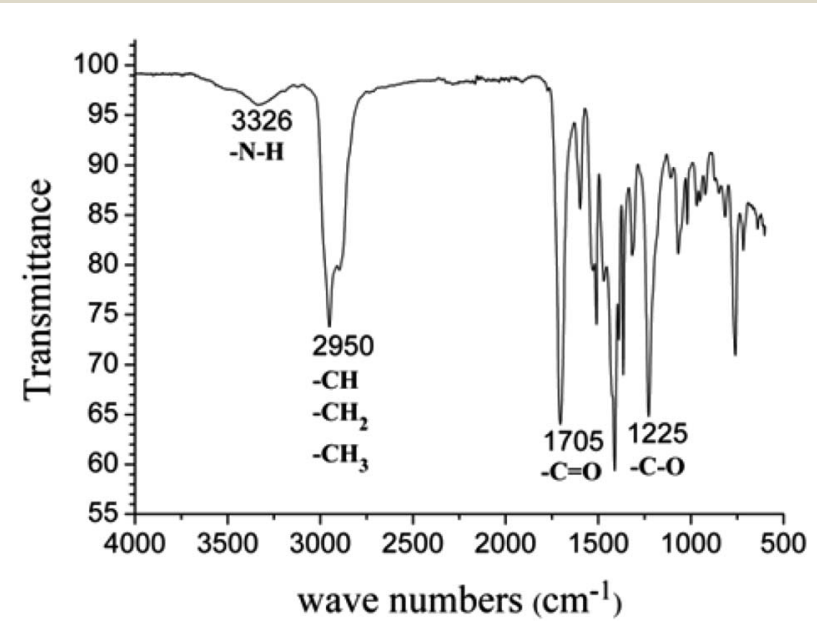

Fig. 14 FT-IR spectrum of the PIB-based polyurethane. 
belonging to PIB and the isocyanate group of MDI. BDO, which is added as a chain extender, reacts with MDI to increase the chain length, and PIB replaces the soft segment of polyurethane. Fig. 13 shows the representative ${ }^{1} \mathrm{H}$ NMR spectrum of the PIB-based polyurethane. The presence of multiplets (NH) at k (8.1 ppm; representing MDI linked to HO-Allyl-PIB-Allyl$\mathrm{OH}$ ) and $\mathrm{j}$ (8.09 ppm; representing MDI linked to BDO) indicate that BDO acts as the chain extender to bond the hard and soft segments of the PIB-based polyurethane. The multiplets at $\mathrm{f}$ $(5.63 \mathrm{ppm})$ and $\mathrm{g}(5.72 \mathrm{ppm})$ are due to $-\mathrm{CH}-\mathrm{CH}=\mathrm{CH}-\mathrm{CH}-$ of the allyl. The disappearance of hydroxymethylene protons at $4.10 \mathrm{ppm}$ and the appearance of the multiplet at e $(4.20 \mathrm{ppm})$

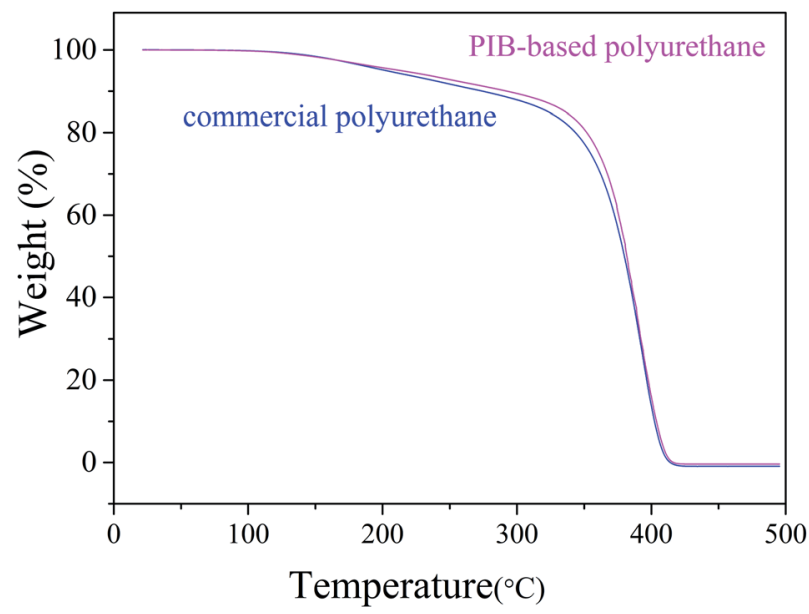

Fig. 15 Comparison of the thermal stabilities of PIB-based and commercial polyurethanes. due to the methylene protons adjacent to $\mathrm{C}=\mathrm{C}$ of the allyl indicate the virtually quantitative formation of urethane linkages. The multiplet at $\mathrm{d}(4.19 \mathrm{ppm})$ due to the methylene protons adjacent to the oxygen of BDO, the singlet at c (3.82 ppm) due to the methylene protons of MDI between the aromatic rings, and the resonance between $\mathrm{i}(7.36 \mathrm{ppm})$ and $\mathrm{h}$ (7.03 ppm) reflect the aromatic protons of MDI and the aromatic protons, respectively, of the initiator used for carbocationic polymerization of Cl-Allyl-PIB-Allyl-Cl. The FT-IR spectra of the polymers in Fig. 14 reveal the absence of -NCO absorption at $2225 \mathrm{~cm}^{-1}$, which indicates complete conversion. Thus, the ${ }^{1} \mathrm{H}$ NMR and FT-IR spectra show that the PIB-based polyurethane elastomer with PIB as the soft segment was successfully synthesized.

As shown in Fig. 15, the thermal stability of the synthesized polyurethane was slightly better than that of commercial polyurethane. We investigated the mechanical properties of the PIBbased and commercial polyurethanes using samples processed before the mechanical tests as follows: acidification: immersion in $\mathrm{HNO}_{3}$ buffer solution for $10 \mathrm{~min}$ at $80{ }^{\circ} \mathrm{C}$; hydrolysis: steam treatment for $96 \mathrm{~h}$ at $85{ }^{\circ} \mathrm{C}$; thermal oxidation: air circulation in $128{ }^{\circ} \mathrm{C}$ furnace for $48 \mathrm{~h}$. Tensile testing was conducted after washing of the products with deionized water and drying in a vacuum oven for $24 \mathrm{~h}$ at $45{ }^{\circ} \mathrm{C}$. Table 1 lists the results of the mechanical test before and after processing. The commercial product had a slightly higher tensile strength than the PIBbased polyurethane due to the presence of flexible PIB segments. However, after processing, the PIB-based polyurethane showed less loss of tensile strength compared with commercial polyurethane. As shown in Table 1, in the acid resistance test, the loss of tensile strength of the PIB-based

Table 1 Tensile strength behavior of PIB-based and commercial polyurethanes before and after testing

Tensile strength $(\mathrm{kPa})$

Acid resistance test

PIB-based polyurethane

Before test

3824

After test

1338

Commercial polyurethane

Loss of tensile strength

Before test

After test

Loss of tensile strength

0

$100 \%$

Hydrolysis stability test

PIB-based polyurethane

Before test

After test

3583

Loss of tensile strength

$6.3 \%$

Commercial polyurethane

Before test

4083

After test

3527

Loss of tensile strength

$13.6 \%$

Thermal oxidation stability test

PIB-based polyurethane

Commercial polyurethane
Before test

After test

Loss of tensile strength

Before test

After test

Loss of tensile strength
3541

$7.4 \%$

4083

3588

$12.1 \%$ 
polyurethane $(64.9 \%)$ after acidification was less than that of commercial polyurethane (100\%), likely because PIB has higher acid resistance than commercial polyurethane. In the hydrolytic stability test, the loss of tensile strength of the PIB-based polyurethane $(6.3 \%)$ after hydrolysis was less than that of commercial polyurethane $(13.6 \%)$. Finally, in the thermal oxidative stability test, the loss of tensile strength of the PIBbased polyurethane $(7.4 \%)$ after processing was less than that of commercial polyurethane $(12.1 \%)$, according to the FT-IR spectra of polymers, it likely due to the increased adsorption coefficient with increasing strength of $\mathrm{H}$ bonding $\left(3326 \mathrm{~cm}^{-1}\right)$ in PIB-based polyurethane is higher than in commercial polyurethane, and the defect caused by the polarity of the ester bonds of commercial polyurethane, thereby making it vulnerable for oxidation and hydrolysis. ${ }^{37-39}$ These results indicate that the soft segment of the polyurethane was replaced with PIB and that the PIB-based polyurethane has better acid resistance and hydrolytic and thermal oxidative stability than commercial polyurethane.

\section{Conclusions}

Cationic polymerization of hydroxyl-terminated telechelic PIB was accomplished in $t$-Bu- $m$-DiCuOMe/ $/ \mathrm{TiCl}_{4}$ initiating systems in the presence of $\mathrm{D} t \mathrm{BP}$ via living cationic polymerization; here, $t$-Bu- $m$-DiCuOMe was used as the high-efficiency initiator. The living PIB chain was capped by BD to form chlorine-terminated telechelic PIB, which was then hydrolyzed with TBAH to form hydroxyl-terminated PIB. NMR confirmed that the hydrolysis was complete, and nearly $100 \%$ conversion of HO-Allyl-PIBAllyl-OH from Cl-Allyl-PIB-Allyl-Cl was observed. Commercial polyurethane suffers from poor hydrolytic and thermal oxidative resistance. PIB-based polyurethane synthesized by using HO-Allyl-PIB-Allyl-OH as a precursor has greater acid resistance and hydrolytic and thermal oxidative stability than commercial polyurethane.

\section{Funding}

This research was funded by the National Natural Science Foundation of China (No. 51573020), Beijing Natural Science Foundation (No. 2182016,2172022), Scientific Research Project of Beijing Educational Committee (KM201810017008), Project of Petrochina (No. KYWK18002).

\section{Conflicts of interest}

There are no conflicts to declare.

\section{References}

1 R. Faust and J. P. Kennedy, Polym. Bull., 1986, 15, 317.

2 S. V. Kostjuk, H. Y. Yeong and B. Voit, J. Polym. Sci., Part A: Polym. Chem., 2013, 51, 471.

3 T. Kelen, M. Zsuga, L. Balogh, I. Majoros and G. Deak, Makromol. Chem., Macromol. Symp., 1993, 67, 325.
4 A. A. Berlin, Y. A. Prochukhan, K. S. Minsker, E. A. Tumanyan, G. G. Aleksanyan and N. S. Yenikolopyan, Polym. Sci., 1988, 30, 2436.

5 J. F. Trant, M. M. A. R. Moustafa, I. Sran and E. R. Gillies, J. Polym. Sci., Part A: Polym. Chem., 2016, 54, 2209.

6 Y. B. Wu, K. Li, D. Xiang, M. Zhang, D. Yang, J. H. Zhang, J. Mao, H. Wang and W. L. Guo, Appl. Surf. Sci., 2018, 445, 8.

7 U. Ojha, R. Rajkhowa, S. R. Agnihotra and R. Faust, Macromolecules, 2008, 41, 3832.

8 S. Banerjee, P. N. Shah, Y. Jeong, T. Chang, K. Seethamraju and R. Faust, J. Chromatogr. A, 2015, 1376, 98.

9 M. Castano, M. L. Becker and J. E. Puskas, Polym. Chem., 2014, 5, 5436.

10 E. Walch and R. J. Gaymans, Polymer, 1993, 34, 412.

11 V. S. C. Chang and J. P. Kennedy, Polym. Bull., 1983, 9, 518. 12 T. J. Deodhar, B. L. Keszler and J. P. Kennedy, J. Polym. Sci., Part A: Polym. Chem., 2017, 55, 1784.

13 B. Iván and J. P. Kennedy, J. Polym. Sci., Part A: Polym. Chem., 1990, 28, 89.

14 A. J. D. Magenau, J. W. Chan, C. E. Hoyle and R. F. Storey, Polym. Chem., 2010, 1, 831.

15 A. A. Albarran, E. Silantyeva, K. S. Seo and J. E. Puskas, Polym. Chem., 2014, 5, 4710.

16 J. E. Puskas, L. B. Brisster, A. J. Michel, M. G. Lanzendorfer, D. Jamieson and W. G. Pattern, J. Polym. Sci., Part A: Polym. Chem., 2000, 38, 444.

17 J. E. Puskas, Y. Chen and M. Tomkins, Eur. Polym. J., 2003, 39, 2147-2153.

18 Y. B. Wu, W. L. Guo, S. X. Li and H. Q. Gong, Chin. J. Polym. Sci., 2009, 27, 399.

19 P. De and R. Faust, Macromolecules, 2006, 39, 6861.

20 X. Y. Wei, P. N. Shah, K. Bagdi, K. Seethamraju and R. Faust, J. Macromol. Sci., Pure Appl. Chem., 2013, 51, 6.

21 N. Nugay, K. Toth, N. C. Kekec, T. Nugay and J. P. Kennedy, J. Polym. Sci., Part A: Polym. Chem., 2016, 54, 2760.

22 X. Y. Wei, K. Bagdi, L. Ren, P. Shah, K. Seethamraju and R. Faust, Polymer, 2013, 54, 1647-1655.

23 L. Ren, N. G. Kang, P. N. Shah and R. Faust, J. Polym. Sci., Part A: Polym. Chem., 2016, 54, 3171.

24 D. Cozzens, A. Luk, U. Ojha, M. Ruths and R. Faust, Langmuir, 2011, 27, 14160.

25 J. P. Kennedy, J. Polym. Sci., Part A: Polym. Chem., 2005, 43, 2951.

26 T. A. Speckhard, P. E. Gibson, S. L. Cooper, V. S. C. Chang and J. P. Kennedy, Polymer, 1985, 26, 55.

27 K. Toth, N. Nugay and J. P. Kennedy, J. Polym. Sci., Part A: Polym. Chem., 2016, 54, 2361.

28 K. T. Kim, T. D. Dao, H. M. Jeong, R. V. Anjanapura and T. M. Aminabhavi, Mater. Chem. Phys., 2015, 153, 291.

29 D. A. Nguyen, A. V. Raghu, J. T. Choi and H. M. Jeong, Polym. Polym. Compos., 2010, 18(7), 351.

30 D. A. Nguyen, Y. R. Lee, A. V Raghu, H. M. Jeong, C. M. Shin and B. K. Kim, Polym. Int., 2009, 58(4), 412.

31 S. K. Jewrajka, J. Kang, G. Erdodi, J. P. Kennedy, E. Yilgor and I. Yilgor, J. Polym. Sci., Part A: Polym. Chem., 2009, 47, 2787.

32 J. Kang, G. Erdodi and J. P. Kennedy, J. Polym. Sci., Part A: Polym. Chem., 2011, 49, 3891. 
33 U. Ojha, P. Kulkarni and R. Faust, Polymer, 2009, 50, 3448. 34 U. Ojha and R. Faust, J. Macromol. Sci., Pure Appl. Chem., 2010, 47, 186.

35 T. Nugay, B. L. Keszler, T. Deodhar, N. Nugay and J. P. Kennedy, J. Polym. Sci., Part A: Polym. Chem., 2017, 55, 3716.

36 R. F. Storey and K. R. Choate, Macromolecules, 1997, 30, 4799.
37 P. Suhas, H. M. Jeong, T. M. Aminabhavi and A. V. Raghu, Polym. Eng. Sci., 2014, 54, 24.

38 A. V. Raghu, G. S. Gadaginamath, M. Priya, P. Seema, H. M. Jeong and T. M. Aminabhavi, J. Appl. Polym. Sci., 2008, 110, 2315.

39 A. V. Raghu, G. S. Gadaginamath and T. M. Aminabhavi, J. Polym. Sci., 2005, 98(5), 2236. 